\title{
Electrochemical, Thermodynamic and Quantum Chemical Studies of Synthesized Benzimidazole Derivative as an Eco- Friendly Corrosion Inhibitor for XC52 Steel in Hydrochloric Acid
}

\author{
Linda Toukal, Saida Keraghel , Fatiha Benghanem, Ali Ourari \\ Laboratoire d'Electrochimie, d'Ingénierie Moléculaire et Catalyse Redox (LEIMCR) \\ Département de Génie des Procédés, Faculté de Technologie, Université Ferhat Abbas Sétif-1 \\ E-mail : $\underline{\text { s_marouani20012002@yahoo.fr }}$
}

doi: $10.20964 / 2018.01 .43$

Received: 20 June 2017 / Accepted: 12 October 2017 / Online Published: 16 December 2017

This work focuses on the study of the inhibitory action of an heterocyclic compound, 1-(4methoxybenzyl)-2-(4-methoxyphenyl)-1H-benzimidazole (MMBI) against corrosion of a steel pipeline sample grade $\mathrm{XC52}$ in a $1 \mathrm{M}$ hydrochloric acid $(\mathrm{HCl})$ solution. The electrochemical methods as the impedance spectroscopy and the potentiodynamic polarization were used to perform this investigation. The effect of the MMBI concentration and the temperature was studied. The determined electrochemical parameters showed that MMBI is a good inhibitor against the corrosion of XC52 steel in $1 \mathrm{M} \mathrm{HCl}$ at a concentrations range from $510^{-6}$ to $10^{-4} \mathrm{M}$ of benzimidazole and temperature ranging from 20 to $60{ }^{\circ} \mathrm{C}$. The inhibiting efficiency $(\mathrm{EI} \%)$ and the apparent activation energy $\left(\mathrm{E}_{a}\right)$ have been calculated in the absence and in the presence of MMBI. The inhibition rate increased with the MMBI concentration to reach $93 \%$ for $10^{-4} \mathrm{M}$ as optimum inhibitor concentration. Potentiodynamic polarizations showed the effect of presence of MMBI on the anodic and cathodic processes suggesting that MMBI can be a mixed type inhibitor. The mechanism of the action of this inhibitor was defined by the thermodynamic study. The calculated values of $\Delta \mathrm{G}_{\text {ads }}^{\circ}, \Delta \mathrm{H}_{\mathrm{a}}, \mathrm{E}_{\mathrm{a}}$ and $\Delta \mathrm{S}_{\mathrm{a}}$ showed that the 1-(4methoxybenzyl)-2-(4-methoxyphenyl)-1H-benzimidazole strongly retards the corrosion of the XC52 steel in $1 \mathrm{M} \mathrm{HCl}$ solution according a chemisorption process. The adsorption phenomenon of this compound on the carbon steel obeys to a Langmuir adsorption isotherm. The quantum chemical parameters were calculated by the Density Functional Theory method (DFT). The experimental and theoretical results are coherent and agree with those of the literature.

Keywords: Corrosion inhibitor, Steel XC52, 2-Aryl-1-arylmethyl-1H-benzimidazole, Potentiodynamic polarization, Impedance spectroscopy, DFT-Calculations. 
(C) 2018 The Authors. Published by ESG (www.electrochemsci.org). This article is an open access article distributed under the terms and conditions of the Creative Commons Attribution license (http://creativecommons.org/licenses/by/4.0/). 